\title{
Experiences and concerns on teaching basics of hemorheology at the Department of Operative Techniques and Surgical Research in Debrecen, Hungary
}

\author{
Norbert Nemeth*, Ferenc Kiss, Katalin Peto, Iren Miko and Istvan Furka \\ Department of Operative Techniques and Surgical Research, Institute of Surgery, Faculty of Medicine, \\ University of Debrecen, Debrecen, Hungary
}

\section{Introduction and background}

Hemorheology is multidisciplinary and strongly needs intuition, associative skills of synthesizing knowledge. Therefore, we believe that the education of its fundamentals is an important task. Opportunities to get experiences, collect ideas and increase knowledge in the field of hemorheology include conferences and congresses, summerschools, workshops, laboratory visits, study trips, reading review articles, handbooks [1-7], guidelines [8], visit internet forums, education pages, educational examples [9] and sporadically there are university seminars and courses, too.

National, continental and international biorheological and hemorheological societies play a highly important role enforcing and distributing this science both in its basic research and clinical research relations. In the last couple of years, gap-filling guidelines and handbooks have been published that also help to obtain widening hemorheological knowledge, distributing its principles, concepts and methods $[4,6,8]$. However, in the medical education there is a lack of hemorheological intention, although many anatomical, physiological, biochemical, molecular biological and pathophysiological relations are well known for the students, too. Synthesis of that knowledge, information on hemorheological variables and interrelation may provide a kind of hemorheological and microcirculatory intention in the diagnostic and therapeutic attitude as well.

\footnotetext{
${ }^{*}$ Corresponding author: Norbert Nemeth, M.D., Ph.D., Department of Operative Techniques and Surgical Research, Institute of Surgery, Faculty of Medicine, University of Debrecen, Nagyerdei krt. 98, H-4032 Debrecen, Hungary. Tel./Fax: +36 52416 915; E-mail: nemeth@ med.unideb.hu; Website: www.surg.res.dote.hu
} 
In this complex process, we believe, that also an important factor is the integration of hemorheological learning into the medical education. Since 2003 at our Department we tend to familiarize basics of hemorheology by several courses at graduate and postgraduate level. In this letter the course programs, experiences and participants' opinions have been summarized.

\section{Educational programs}

\subsection{Courses at graduate level}

Since 2003 one lecture and consecutive seminar/practice of basic hemorheological methodology have been included into our subject entitled „Basic Knowledge of Medical Tools and Surgical Biomaterials for Pharmacotherapeutical Surgical Care" (8 weeks) taught for the students of the Faculty of Pharmacy.

Since the 2006/2007 academic year a freely chosen elective course „Basics of Hemorheology” (10hour) had been started announced for the general medical students of the Faculty of Medicine students both in Hungarian and English Programs. The course program is summarized in Table 1.

In the subject „Basics of Animal Experimentation” (15 weeks) for biomedical research analyst students: one meeting with lecture, seminar and laboratory practice is dedicated to the hemorheology, being as an obligatory part of the course since the 2007/2008 academic year.

From the academic year 2013/2014 we started a new subject (required for biomedical research analyst students) entitled "Rheology of the Blood and the Lymphatic Circulation" (15 lectures and 15 practices). The detailed program is shown in Table 2.

\subsection{Courses and seminars at postgraduate level}

Since 2003 one lecture on hemorheology and microcirculation (related to surgical interventions) is included into the residency program of operative medicine.

We also organize a 14-hour Ph.D. course entitled „Hemorheological and microcirculatory relations of ischemia-reperfusion" since the 2006/2007 academic year, of which program is similar to the graduate course, but with extended theoretical and practical issues.

Table 1

The program of the 10-hour course "Basic of hemorheology" for general medical students

\begin{tabular}{ll}
\hline Lectures & Topic \\
\hline I & Historical background, definitions and basic conceptions of hemorheology \\
& Hemorheological variables \\
II & Apects of blood sampling \\
& Hemorheological measurement techniques and conditions \\
& Demonstration of measurements (laboratory) \\
III $\quad$ Hemorheological aspects and measurement conceptions in laboratory animal science (Sampling, species specific \\
IV $\quad$ differences, adaptation of measurements) \\
\\
Vanges of whole blood and plasma viscosity, erythrocyte deformability and aggregation in various \\
pathophysiological processes and diseases \\
Analyses of hemorheological and microcirculatory alterations during and after organ/tissue ischemia-reperfusion - \\
experimental data
\end{tabular}


Table 2

The program of the 30-hour course "Rheology of the blood and the lymphatic circulation" for biomedical research analyst students

\begin{tabular}{ll}
\hline Class type & Topic \\
\hline Lectures (15 hours) & History of rheology and hemorheology \\
& Physical basics for understanding rheology \\
& Blood and plasma viscosity \\
& Red blood cell deformability \\
& Red blood cell aggregation \\
& Relation between rheological parameters and the endothelial function \\
& In vivo hemorheology \\
& Rheology of the microcirculation \\
& Rheology of the lymphatic circulation \\
& Hemorheological changes in pathophysiological processes \\
& Current research topics in biorheology and clinical hemorheology (article reviews in small groups) \\
& Rheological, hemorheological measurement methods: \\
& Viscometers \\
& Methods for measuring red blood cell deformability \\
& Methods for measuring red blood cell aggregation \\
& Sampling, handling and sample storage principles for hemorheological measurements \\
& Sample preparation for measurements: buffers and suspension solutions \\
& Measurement of blood and plasma viscosity by a capillary viscometer Measurement of red blood cell \\
& deformability by filtrometry and by slit-flow and rotational ektacytometer. Testing membrane \\
(mechanical) stability and osmotic gradient ektacytometry & Measurement of red blood cell aggregation by light-transmission aggregometry and laser \\
& backscattering method
\end{tabular}

\section{Experiences and opinions}

In the hemorheological education programs a high number of students took part in the last 10 years: 526 pharmacy students (lecture\&seminar), 110 biomedical research laboratory analyst students (lecture\&seminar: 93; 30-hour course: 17), 245 medical students (hemorheology course), 329 residents (lecture), $54 \mathrm{Ph} . \mathrm{D}$. students (hemorheology course).

The 10-hour medical student course anonymous rating score (min. 0 - max. 10) average was: 9.69. The 14-hour Ph.D. course anonymous rating score average was: 9.93.

Featured opinions, mostly positive: "Participating in this course, has increased my clinical knowledge about hemorheology."; "Research oriented, but on the other hand clinically relevant and useful material which interconnect lab and research data to patient management and clinical skills."; "It was a very interesting course, giving valuable information that we can use in our medical practice."; "It was really an eye opener for me as regards research \& the significance of microcirculation in surgery. I found it very relevant."; "It was a nice perspective on a topic that is neglected in other topics."; "Very good and interesting course. I study a lot from this course (before this course I didn't know what is it hemorheology)."; "Very interesting \& great new perspective of microcirculatory \& ischemic-reperfusion injuries. Gave me other things to think about when it comes to working in the operative theatre."; "I look forward to writing my thesis here." 
Very few "negative" rather improving comments were got, e.g. "It will be better if we have written material."; "More practice would be needed"; "Would like to see more video of the experiment and the animations."

\section{Concluding thoughts}

We believe that teaching and -according to possibilities- the more wide-spreading integration of hemorheology can be gap-filling and important in forming and spreading hemorheological point of view both for the clinicians and the researchers. According to our hopes, out of the undergraduate and Ph.D. students, who take hemorheological courses, will be some, who may show more interest towards this field and will start or continue their research work in hemorheology.

Unfortunately the number of the active participants in the hemorheological associations and societies is relatively low, the cooperating-collaborating relations are narrowing and it is getting harder to attain grants focusing on hemorheological issues. Therefore, maybe it would worth to deal more with educational issues on different hemorheological congresses, since the raising of the new generation is of high importance in every field of science. And in hemorheology it is a critical question ...

\section{Acknowledgments}

Special thanks to Prof. Sándor Imre (Debrecen, Hungary), Prof. Kálmán Tóth, Prof. Lajos Bogár and Prof. Lajos Kollár (Pécs, Hungary).

The first author would like to say special thanks also to Prof. Herbert J. Meiselman (Los Angeles, USA), to Prof. Sandro Forconi (Siena, Italy) and in memoriam to Prof. Oguz K. Baskurt (Antalya and Istanbul, Turkey).

The authors comply with the Ethical Guidelines for Publication in Clinical Hemorheology and Microcirculation as published on the IOS Press website and in Volume 44, 2010, pp. 1-2 of this journal.

Grants: KPÖ 0147/2006, Hungarian State Eötvös Fellowship 61/2007, BILAT TR-03/2006, János Bolyai Research Scholarship of the Hungarian Academy of Sciences.

\section{References}

[1] A klinikai haemorheologia alapjai, S.I. Bernát and E. Pongrácz, eds, Kornétás Kiadó, Budapest, Hungary, 1999.

[2] Clinical Blood Rheology, G.D.O. Lowe, ed, CRC Press, Boca Raton, USA, 1988.

[3] Clinical Hemorheology, S. Chien, J. Dormandy, E. Ernst and A. Matrai, eds, Martinus Nijhoff Publ., Dordrecht, 1987.

[4] Handbook of Hemorheology and Hemodynamics, O.K. Baskurt, M.R. Hardeman, M.W. Rampling and H.J. Meiselman, eds, IOS Press, Amsterdam, The Netherlands, 2007.

[5] Hemorheology in Practice, J.F. Stoltz, M. Singh and P. Riha, eds, IOS Press, Amsterdam, The Netherlands, 1999.

[6] Red Blood Cell Aggregation, O. Baskurt, B. Neu and H.J. Meiselman, eds, CRC Press, Boca Raton, USA, 2012.

[7] Therapeutic Hemorheology, A.M. Ehrly, ed, Springer-Verlag, New York, USA, 1991.

[8] O.K. Baskurt, M. Boynard, G.C. Cokelet, P. Connes, B.M. Cooke, S. Forconi, M.R. Hardeman, F. Jung, F. Liao, H.J. Meiselman, G. Nash, N. Nemeth, B. Neu, B. Sandhagen, S. Shin, G. Thurston and J.L. Wautier, New guidelines for hemorheological laboratory techniques, Clin Hemorheol Microcirc 42 (2009), 75-97.

[9] L.N. Toksvang, R.M.G. Berg, Using a classic paper by Robin Fåhraeus and Torsten Lindqvist to teach basic hemorheology, Adv Physiol Edu 37 (2013), 129-133. 